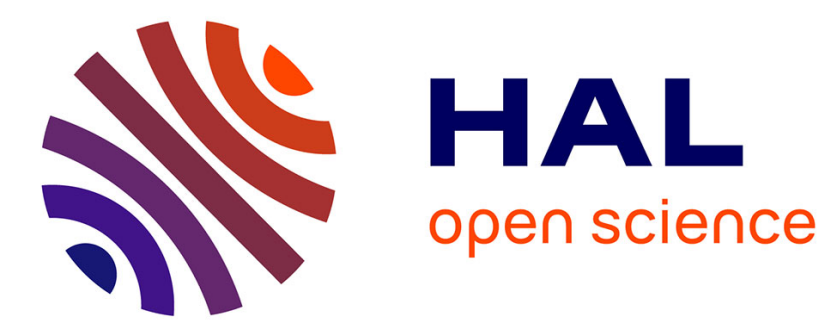

\title{
Nanoimprint process using epoxy-siloxane low-viscosity prepolymer
}

Benoit Viallet, Pascal Gallo, Emmanuelle Daran

\section{To cite this version:}

Benoit Viallet, Pascal Gallo, Emmanuelle Daran. Nanoimprint process using epoxy-siloxane lowviscosity prepolymer. Journal of Vacuum Science \& Technology B Microelectronics and Nanometer Structures, 2005, 23 (1), pp.72-75. 10.1116/1.1835319 . hal-03327494

\section{HAL Id: hal-03327494 \\ https://hal.laas.fr/hal-03327494}

Submitted on 27 Aug 2021

HAL is a multi-disciplinary open access archive for the deposit and dissemination of scientific research documents, whether they are published or not. The documents may come from teaching and research institutions in France or abroad, or from public or private research centers.
L'archive ouverte pluridisciplinaire HAL, est destinée au dépôt et à la diffusion de documents scientifiques de niveau recherche, publiés ou non, émanant des établissements d'enseignement et de recherche français ou étrangers, des laboratoires publics ou privés. 


\title{
NANOIMPRINT PROCESS USING EPOXY-SILOXANE LOW VISCOSITY PRE-POLYMER
}

Benoît Viallet, Pascal Gallo, Emmanuelle Daran

LAAS/CNRS - 7, avenue du Colonel Roche 31077 Toulouse CEDEX 04 - France

\begin{abstract}
In conventional nanoimprint lithography, relatively high pressures and high temperature are used for embossing thermoplastics. However, this may induce mechanical strain in the mould and sample, and prohibits patterning of fragile substrates. Polymer flow in the viscoelastic regime is quite a slow process that can also limit patterning performances. To overcome these difficulties a low pressure, and moderate temperature imprint process using new low viscosity thermocurable epoxy-siloxane pre-polymer is proposed. We demonstrate replicated patterns with $60 \mathrm{~nm}$ lines and $150 \mathrm{~nm}$ space, and less than $10 \mathrm{~nm}$ residual layer. The low viscosity process also allows for the simultaneous replication of micrometre and nanometre scaled patterns. Transfer onto silicon substrate via reactive ion etching or lift-off is possible without removing the residual layer.
\end{abstract}




\title{
NANOIMPRINT PROCESS USING EPOXY-SILOXANE LOW VISCOSITY PRE-POL YMER
}

\author{
B. Viallet, P. Gallo, E. Daran \\ LAAS/CNRS - 7, avenue du Colonel Roche 31077 Toulouse CEDEX 04 - France
}

\section{INTRODUCTION}

The imprint lithography technologies (NIL), introduced by Chou et al. in 1995 [1], may be used to overcome the feature size limitation encountered in classical photolithography while remaining more economical than lithographies based on electron, ion beam, $x$-ray, and scanning probe tips.

In the approach involving hot-embossing of a thermoplastic resist layer, a sub-10nm [2] resolution has been achieved, but difficulties, due to polymer flow, have also been identified with the replication of large patterns [3], the use of negative moulds (with a large protruding surface) [4], and the minimization of residual thickness. However, owing to the high viscosity of the thermoplastic resist, even well above glass temperature $\left(\mathrm{T}_{\mathrm{g}}\right)$, high pressures between 50 bar and 100 bar [5] are needed. These conditions increase the risk of deformation or damage to flimsy substrates, and they may affect predefined structures in a multilevel lithography process thus becoming detrimental to potential applications.

Alternatives to hot-embossing like room-temperature nanoimprint lithography (RT-NIL) [6] or imprint using ultraviolet-curable liquid polymer [7] have been proposed. The RT-NIL solution has been developed to overcome critical dimension and pattern placement error due to thermal expansion in the conventional NIL process. RT-NIL using Hydrogen Silsesquioxane (HSQ) [8] demonstrates replicated patterns with $90 \mathrm{~nm}$ hole diameter and $50 \mathrm{~nm}$ line width but the pressure applied is still high (2.5 to 4.5 MPa) and residual depth is $150 \mathrm{~nm}$ with a thickness contrast of 1:1 compared to the pattern height. Likewise, the RT-NIL process developed with Hybrane (HS2550) [9] cannot be achieved at low pressure, because of poor thickness contrast. Nevertheless with a three step pressure application (10, 20 and 30 bar) a high density pattern replication (gratings of $75 \mathrm{~nm}$ line and spacing) can be obtained. Processes based on photo-induced solidification also avoid thermal expansion but the residual depth of the resist is high and inhomogeneous in thickness for large processed surfaces [10]. This limitation was the main motivation to a stepping procedure known as "step and flash" imprint lithography [11] that requires more complex patterning tools.

In this paper, a low pressure, moderate temperature imprint process is presented, based on moulding low viscosity prepolymer materials. The benefits of this type of prepolymer are reported, with the demonstration of simultaneous production of nm-scaled patterns adjacent to $\mu \mathrm{m}$-scaled structure and of ultra-thin residual layer.

\section{POLYMER FORMULATION}

Nanoimprint with thermocurable polymer consists in dispensing a pre-polymer mixture to the substrate, pressing a mould on that substrate, curing the polymer at controlled temperature and removing the mould. The resulting polymer pattern can be used as a mask for etching, for a lift-off process or directly if its properties are suitable for the application desired. In this study, we have developed a polymer for etching and lift-off processes.

Thus, the polymer properties must match a number of requirements. The viscosity of the prepolymer mixture must be as low as possible, while curing time and temperature must be maintained as low as possible. The polymer must be rigid to avoid deformation of the pattern and exhibit a good adhesion on different substrates (silicon, silica, GaAs, organic layers). The chemical structure of the 
polymer must allow for wet etching in organic or aqueous solution, for lift off and polymer elimination. This polymer must also be resistant to reactive ion etching (RIE).

Poly(dimethyl-siloxane) (PDMS) had shown good properties for NIL[12]. Its low viscosity, combined with a short curing time, a good resistance to RIE etching and its sensitivity to $\mathrm{H}_{2} \mathrm{SO}_{4}$ for elimination were advantages in this process. Nevertheless, sub-200nm patterns could not be replicated satisfactorily, and the adherence onto organic layers was not adequate.

Going further in terms of resolution means improving the polymer structure while keeping most PDMS properties. For accurate moulding, we designed a solution that preserves the siloxane basis but reinforces the material through an epoxy-amine crosslinking chemistry. With this system, the polymer properties can easily be modified by adjusting the amine formulation which enables this material to be better engineered to optimise performances.

Chemical formulation of pre-polymer used in this study are given in Figure 1. The siloxane chain: bis(dimethylsiloxane)epoxypropoxypropyl terminated (DMS-DGE), is functionalised with epoxy groups. This molecule is polymerised with diamine: 1.3-bis(aminomethyl)cyclohexane (BAC) or 1,3-bis(aminomethyl)benzene (BAB). All compounds are liquid and the viscosity of each component is between $1 \mathrm{mPa}$.s and $9 \mathrm{mPa} . \mathrm{s}$ at $20^{\circ} \mathrm{C}$ which is comparable to the viscosity of water. The glass transition temperature $\left(T_{g}\right)$ of DMS-DGE polymerised with $\mathrm{BAC}$ is $-3^{\circ} \mathrm{C}$ and with $\mathrm{BAB},-8^{\circ} \mathrm{C}$. $\mathrm{T}_{\mathrm{g}}$ were measured by differential scanning calorimetry. Both amines (BAC and $\mathrm{BAB}$ ) were supplied by Sigma-Aldrich and DMS-DGE by ABCR.

\section{EXPERIMENTAL}

Imprint masters were fabricated by high resolution Electron Beam Lithography (EBL) in PMMA resist and subsequent reactive ion etching. Before etching, positive masks were inversed by lift-off of a $20 \mathrm{~nm}$ chromium layer. Because EBL is performed with a modified STEM, only $4 \times 4 \mathrm{~mm}^{2}$ masters could be processed. Etching depth varies from $80 \mathrm{~nm}$ to $150 \mathrm{~nm}$ according to pattern definition. After etching, moulds were coated with an octadecytrichlorosilane (OTS) [13-14] molecular layer ensuring efficient anti-adhesion properties of the surface. Before coating, moulds were cleaned as follows: PMMA or chromium removal, ultrasonicated acetone bath, oxygen plasma, and de-ionised water rinse. This treatment is important to create hydroxyl groups at the silicon surface in order to graft OTS molecules. OTS coating was done by dipping the mould in a $1 \%$ OTS solution in trichlorethylene.

The patterns reported here were printed on silicon substrates prepared using a solvent ultrasonicated cleaning bath, and $\mathrm{H}_{2} \mathrm{SO}_{4}+\mathrm{H}_{2} \mathrm{O}_{2}$ in order to improve surface energy and adhesion of the imprinted layer.

The concentration of DMS-DGE and amine was chosen to obtain the stoechiometric proportion of two epoxy groups for one primary amine. The pre-polymer components were mixed and the mixture subsequently inserted in a primary vacuum chamber in order to remove bubbles trapped in the material. A $0.5 \mu \mathrm{l}$ drop was laid on the mould. Substrate and mould were pre-heated for $2 \mathrm{~min}$ at curing temperature to prevent liquid demixing. Both surfaces were brought into contact and pressed in a conventional hydraulic press. Epoxy-siloxane resist was pressed and cured for 4 hours at $100^{\circ} \mathrm{C}$ or 2 hours $30 \mathrm{~min}$ at $120^{\circ} \mathrm{C}$. Curing temperature and time could be further reduced by using a suitable catalyst. The pressure in these experiments was 15 bars as the lower pressure correctly controlled in our experimental system.

Metal deposition for lift-off was carried out by an ion beam sputtering system. The residual layer of polymer left under the imprinted features, if any, was removed by ion beam etching using 3 $\mathrm{keV}$ argon ion beam. Polymer etching for lift-off was done by dipping the sample in a sulphuric acid solution under ultrasound agitation. 


\section{RESULTS AND DISCUSSION}

OTS surface treatment of silicon masters yields to a contact angle of water between $106^{\circ}$ and $109^{\circ}$. Surface energy, measured by a three liquid contact angle method [15] is less than $25 \mathrm{~mJ} / \mathrm{m}^{2}$. A systematic measurement of contact angle of water prior to each imprint process allows to check the release characteristics of the surface treatment and enables successive uses of the same master. A contact angle of water above $100^{\circ}$ ensure an easy release of the mould from polymer. Moreover, the elastomer property of the epoxy-siloxane material facilitates the mould release.

Figure 2 shows the scanning electron microscopy (SEM) image of a $150 \mathrm{~nm}$ lines and spaces grating imprinted with DMS-DGE and BAC pre-polymer. The total length of the grating is $800 \mu \mathrm{m}$, and line height is $150 \mathrm{~nm}$. Rounded ends of lines reflect the master shape. This pattern shows well defined edges, and compliance with the master definition. Without particular precaution, no polymer void nor bubbles have been observed on the imprinted samples. The residual thickness obtained when using negative master (with a large protruding surface) is less than $20 \mathrm{~nm}$, with a very high thickness contrast ( 7:1) compared to UV-based imprint technique. A high thickness contrast will help in the removal of the residual layer in a subsequent etch process. Polymers composed by DMS-DGE and $\mathrm{BAC}$ or $\mathrm{BAB}$ exibit similar results.

The imprinting performance of prepolymers has been reviewed by looking at the mimimun transfer feature size and the ability to imprint $\mathrm{nm}$-scaled patterns adjacent to $\mu \mathrm{m}$-scaled structures. The best resolution obtained is $60 \mathrm{~nm}$ interdigitated lines with a $200 \mathrm{~nm}$ pitch, pattern height being $80 \mathrm{~nm}$. A typical result is given in Figure 3. Imprinting smaller and denser patterns (50 nm with a period of $150 \mathrm{~nm}$ ) leads to line deformation with a two-by-two collapse. For smaller lines ( $25 \mathrm{~nm}$ with $100 \mathrm{~nm}$ period), the resulting pattern is a smooth waveform. The lack of definition is caused by pattern deformation due to the elastomer characteristic of the epoxy-siloxane resist. To improve resolution $T_{g}$ or Young modulus of the polymer below the $\mathrm{T}_{\mathrm{g}}$ has to be increased by adjusting formulation.

A master containing $60 \mathrm{~nm}$ interdigited electrodes and $100 \mu \mathrm{m} \times 100 \mu \mathrm{m}$ adjacent connecting pads has been successfully imprinted without optimisation of the material and procedure process. Whatever the shape and size of the imprinted patterns, residual thickness is kept low. For example, the same process can be applied to positive and negative master, demonstrating that material transport problems are not restricting the moulding process when using very low viscosity material. This low residual thickness will be taken advantage of for lift-off and for the dimensional control of the features produced.

To remove the thin residual layer of polymer, in case of negative mould use, argon ion etching has been performed for $1 \mathrm{~min}$. The patterned polymer layer thus obtained can be subsequently used as a mask for wet or dry etching. For preliminary experiments of RIE, we used a $\mathrm{SF}_{6} / \mathrm{O}_{2}$ gas mixture and we obtained an etching rate of PDMS-DGE/BAB two times less than that of silicon. Patterns have also been transferred into the silicon wafer by lift-off of a $20 \mathrm{~nm}$ thick chromium layer and RIE, the polymer being dissolved with a sulphuric acid solution in deionized water under ultrasound agitation. Figure 4 shows a $300 \mathrm{~nm}$ pitch grating after imprinting and lift-off. To lift off the metal after imprinting with a negative master, the residual layer had to be etched. But using a positive master (with a small bulging surface), lift-off has been possible without etching. This is illustrated in Figure 5 where the poor definition of the edges is due to the presence of metal flags (due to of metal deposition on the resist wall) and to the mould definition. These flags appear to be enhanced by lack of residual layer RIE. The use of positive master and a fluid pre-polymer mixture leads to a residual thickness which is sufficiently low to bypass the etching step after imprinting.

\section{CONCLUSION}

A new type of pre-polymer has been used as a thermocurable resist for low pressure, moderate temperature imprint lithography process. It has been shown that very thin residual layer (less than 10 $\mathrm{nm}$ ) can be obtained, allowing transfer process without etching of the base layer when positive moulds are used. Micrometer and nanometre scaled patterns can be obtained simultaneously with a very good 
thickness contrast in the case of positive and negative mould. The imprinted structures are transferred onto silicon using conventional RIE or lift-off process.

By adjusting the pre-polymer formulation, the material properties could be further modified to meet specific requirements for various applications : better resolution, higher etching resistance, ...

The results show that the nanoimprinting process using epoxy-siloxane is particularly useful for creating nanometre scaled patterns on low mechanical resistance substrate and to create, simultaneously, nanometre and micrometre features.

\section{ACKNOWLEDGEMENTS}

The authors would like to thank Monique Mauzac and Anne-Françoise Mingotaud for valuable discussions about polymer formulation and differential scanning calorimetry measurements. The authors are also grateful to Franck Carcenac for the mould fabrication and Pascal Dubreuil for the RIE tests. 


\section{FIGURES}

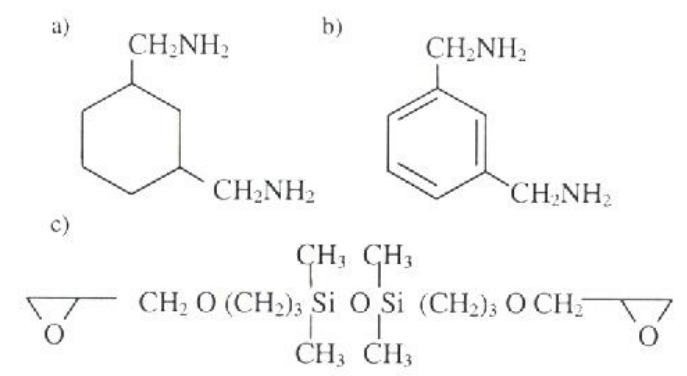

Figure 1 : Chemical formulation of the pre-polymer used in this study a) 1.3-bis(aminomethyl)cyclohexane $(\mathrm{BAC})$ b) 1,3-bis(aminomethyl)benzene $(\mathrm{BAB})$ c) bis(dimethylsiloxane)epoxypropoxypropyl terminated (DMS-DGE).

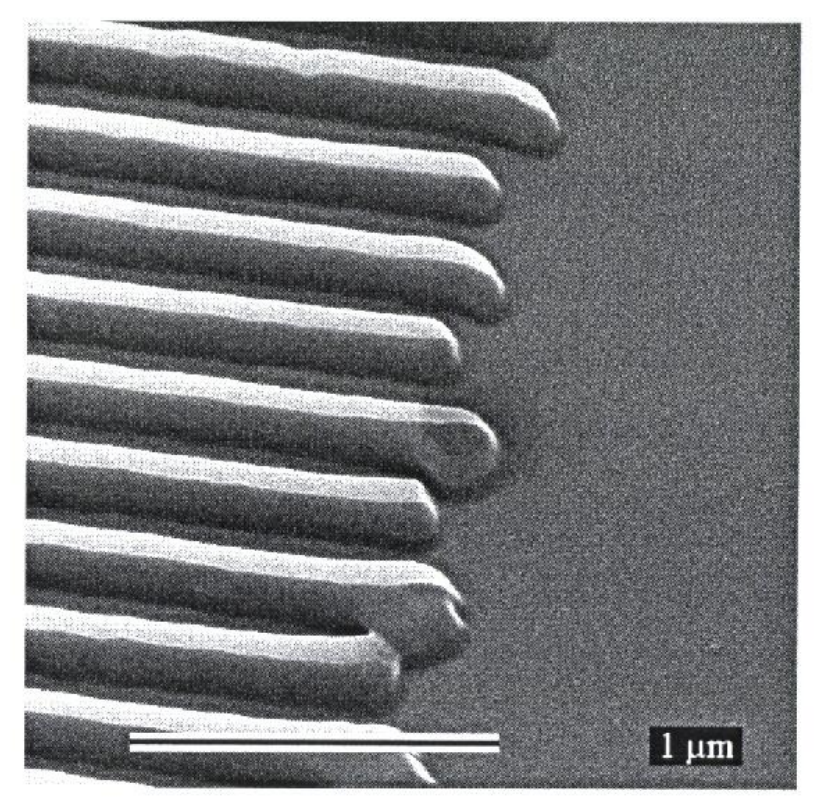

Figure 2: $150 \mathrm{~nm}$ line and space pattern imprinted with DMS-DGE and BAC 

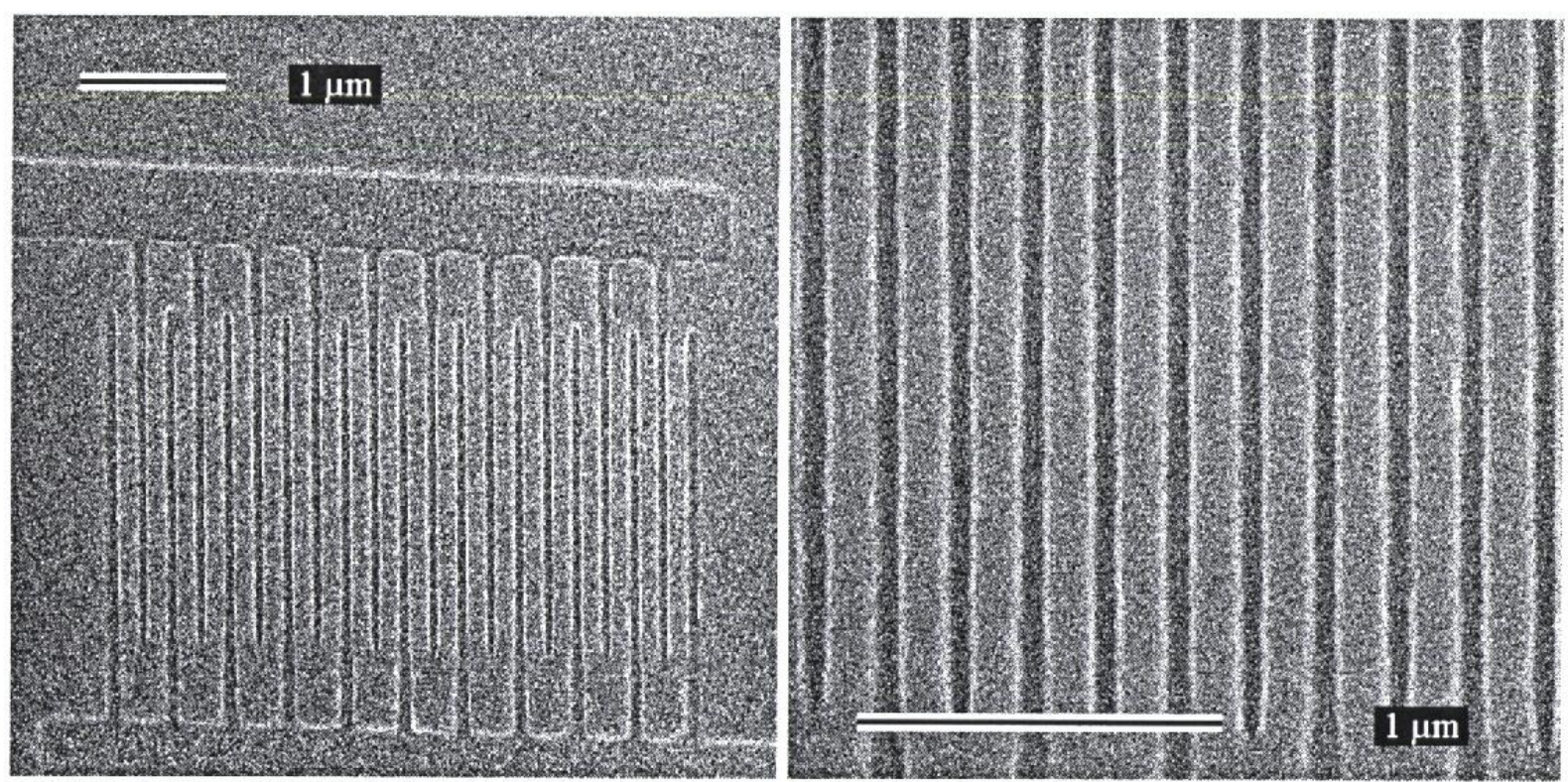

Figure $3: 60 \mathrm{~nm}$ interdigited lines with a $200 \mathrm{~nm}$ period. On the right, magnified printed lines shows the smooth and good definition of edges
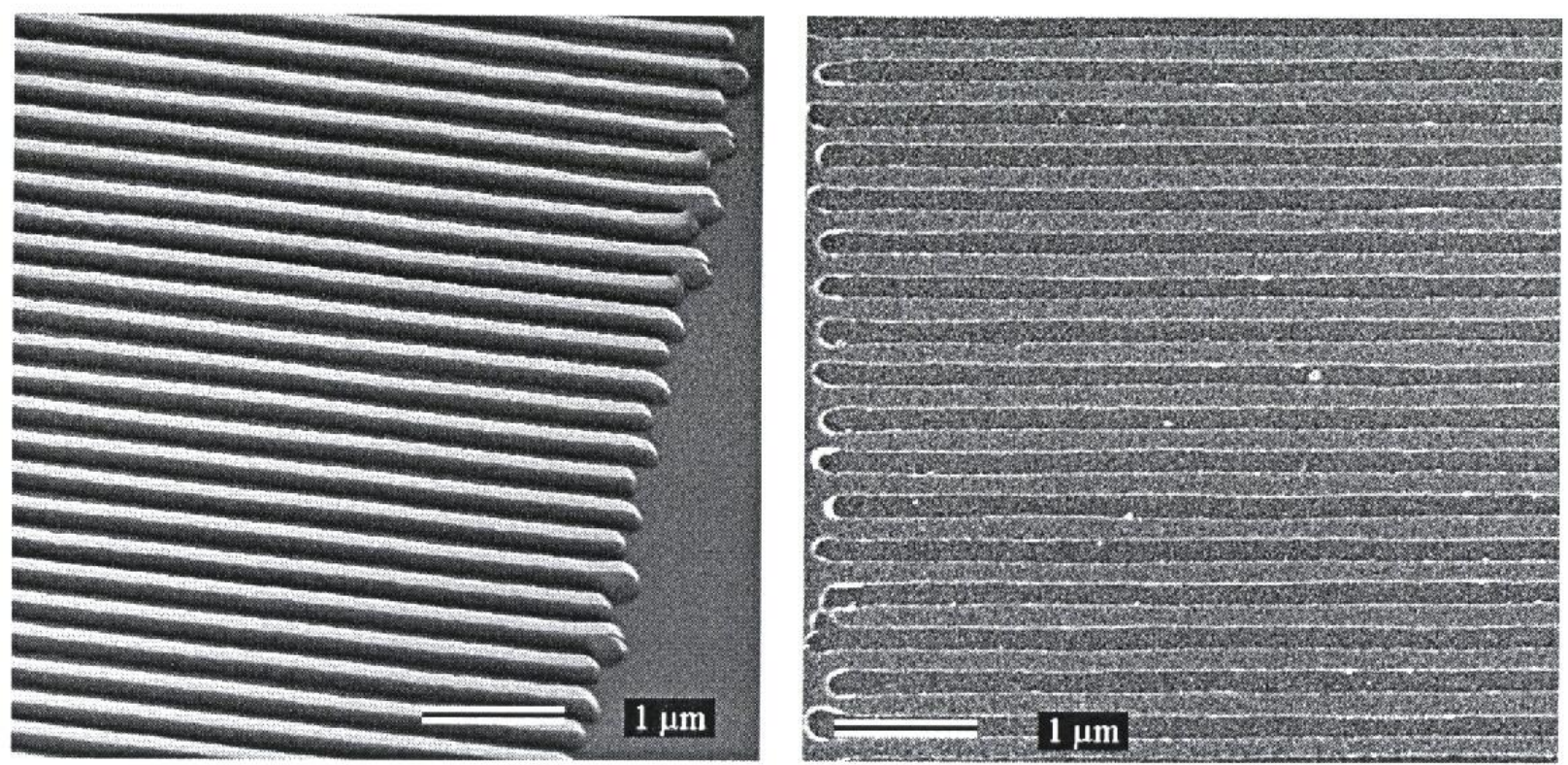

Figure $4: 300 \mathrm{~nm}$ pitch grating just after imprinting and after lift-off of a $20 \mathrm{~nm}$ thick chromium layer 


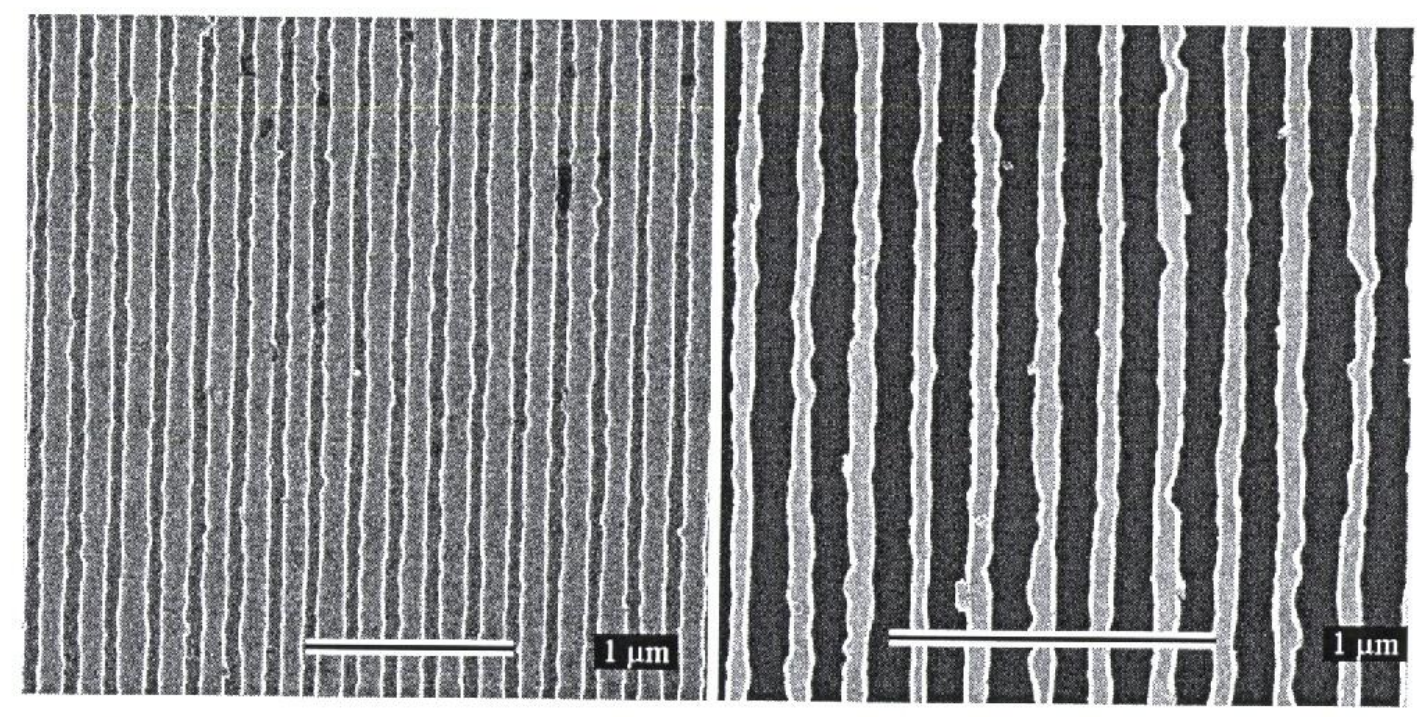

Figure $5: 200 \mathrm{~nm}$ period lines after imprint and lift-off without etching any residual layer. The left image represents the master and the right the results after imprinting and lift-off. 


\section{REFERENCES}

[1] S.Y. Chou, P.R. Krauss, P. J. Renstrom, Appl. Phys. Lett. 67, 3114 (1995)

[2] S.Y. Chou, P.R. Krauss, W. Zhang, L. Guo, L. Zhuang, J. Vac. Sci. Technol. B 15(6), 2897 (1997).

[3] H.-C. Scheer, H. Schulz, Microelectron. Eng. 56, 311 (2001).

[4] H.-C. Scheer, H. Schulz, T. Hoffmann, C.M. Sotomayor Torres, J. Vac. Sci. Technol. B 16(6), 3917 (1998).

[5] C.M. Sotomayor Torres, S. Zankovych, J. Seekamp, A.P. Kam, C. Clavijo Cedeño, T. Hoffmann, J. Ahopelto, F. Reuther, K. Pfeiffer, G. Bleidiessel, G. Gruetzner, M.V. Maximov, and B. Heidari, Mater. Sci. Eng. C 23, 23 (2003)

[6] D-Y Khang and H.H. Lee, Appl. Phys. Lett. 76, 870 (2000)

[7] M. Bender, M. Otto, B. Hadam, B. Vratzov, B. Spangenberg, and H. Kurz, Microelectron. Eng. 53, 233 (2000)

[8] S. Matsui, Y. Igaku, H. Ishigaki, J. Fujita, M. Ishida, Y. Ochiai, H. Namatsu, M. Komuro, J. Vac. Sci. Technol. B 21 (2), 688 (2003)

[9] A. Lebib, Y. Chen, E. Cambril, P. Youinou, V. Studer, M. Natali, A Pépin, H.M. Janssen, R.P. Sijbesma, Micoelectron. Eng. 61-62, 371 (2002)

[10] J. Haisma, M. Verheijen, K. Van den Henvel, and J. Van den Berg, J. Vac. Sci. Technol. B 14, 4124 (1996)

[11] T. Bailey, B. J. Choi, M. Colburn, M. Meissl, S. Shaya, J.G. Ekerdt, S.V. Sreenivasan, and C.G. Wilson, J. Vac. Sci. Technol. B 18(6), $3572(2000)$

[12] L. Malaquin, F. Carcenac C. Vieu, M. Mauzac, Microelectron. Eng. 61-62, 379 (2002)

L. Malaquin, C. Vieu, Alternative lithography, published by C.M. Sotomayor Torres ( Kluwer academic publishers, Boston/Dordrecht/London, 2003), pp. 164-199, Using PDMS as a thermocurable resist for a mold assisted imprint process

[13] X. Zhao, R. Kopelman, J. Phys. Chem. 100, 11014 (1996)

[14] Y. Liu, K. Wolf, M. Messmer, Langmuir 17, 4329 (2001)

[15] C. J. van Oss, Interfacial Forces in aqueous media, (M. Dekker, New York, 1994) 